\title{
Assimetria de informação e desempenho
}

\author{
Um estudo em empresas de capital aberto \\ no Brasil
}

por Claudineia Kudlawicz-Franco, Tatiana Bach e Eduardo Silva

RESUMO: Este estudo objetiva analisar a influência da assimetria de informação no desempenho econômico de empresas de capital aberto, com ações negociadas na BM\&FBOVESPA. Criaram-se variáveis proxies para assimetria de informação, além das variáveis representativas do desempenho econômico, retorno sobre o patrimônio líquido (ROE) e retorno sobre o ativo. A coleta de dados foi realizada por meio do software Economática, dos websites das empresas e da BOVESPA e, para a análise dos dados, foi realizada a regressão linear múltipla. Os principais resultados inferem que o desempenho das empresas quando representado pelo ROE é influenciado pela assimetria de informação, mas somente pela proxy índice de governança, indicando que, se a governança corporativa das empresas é mais transparente, o ROE aumenta.

Palavras-chave: Teoria da Agência; Informação Assimétrica; Retorno do Ativo; Retorno sobre Patrimônio Líquido

\section{La información asimétrica} y el rendimiento

\section{Un estudio en empresas de capital abierto en Brasil}

RESUMEN: Este estudio tiene como objetivo analizar la influencia de la información asimétrica en los resultados económicos de las empresas de capital abierto, con acciones negociadas en la BM\&FBOVESPA. Fueron creadas variables proxies para la información asimétrica, además de las variables representativas de los resultados económicos, rentabilidad sobre capitales propios (ROE) y el retorno sobre activos. La recolección de datos se llevó a cabo a través del software Economática, los sitios web de las empresas y el BOVESPA y, para el análisis de datos, fue realizada una regresión lineal múltiple. Los principales resultados deducen que el desempeño de las empresas representadas por el ROE está influenciado por la información asimétrica, pero sólo por el índice de gobernabilidad del proxy, lo que indica que, si el gobierno corporativo de las empresas es más transparente, el ROE aumenta.

Palabras clave: Teoría de la Agencia; Información Asimétrica; Rendimiento de los Activos; El Retorno sobre Capital 


\section{Asymmetric information and performance A study in public companies in Brazil}

ABSTRACT: This article draws on experiences undertaken in Brazil to show how people, who are socially excluded or disadvantaged, can have a bigger chance of success in professional careers in large organizations if they have received training in classical music. The research focuses on the perception of success and the transformation of values in Brazilian projects that provide young people from poor communities with classical music tuition. The analysis focuses on the perceptions of success of classical music projects geared towards socially disadvantaged people with the aim of facilitating their upward social mobility and reducing their feeling of exclusion. The results reveal some significant value transformations. The socially disadvantaged children and youth acquire: (1) a new perspective of their self, with greater self-confidence and self-esteem; (2) a greater willingness to aim for long-term benefits and less delusion about short-term benefits; (3) a new motivation to learn; (4) a new perspective on the concept and practice of discipline; and (5) a new balance between the values of competition and cooperation.

Key words: Agency Theory; Asymmetric Information; Return on Assets; Return on Equity

Claudineia Kudlawicz-Franco

kclaudineia@gmail.com

Doutoranda em Administração, Pontifícia Universidade Católica do Paraná, Rua Imaculada Conceição, 1155, Bloco Acadêmico, Sala 103 B, 1.o, Prado Velho - Curitiba, PR, CEP: 80215-901, Brasil.

Estudiante de doctorado en Administración de Empresas, Pontifícia Universidade Católica do Paraná, Rua Imaculada Conceição, 1155, Bloco Acadêmico, Sala 103 B, 1.․,

Prado Velho - Curitiba, PR, CEP: 80215-901, Brasil. $\mathrm{PhD}$ candidate in Business Administration, Pontifical Catholic University of Parana, Rua Imaculada Conceição, 1155, Bloco Acadêmico, Sala 103 B, 1. , Prado Velho Curitiba, PR, CEP: 80215-901, Brazil.

Tatiana Marceda Bach tatibach@gmail.com

Doutoranda em Administração, Pontifícia Universidade Católica do Paraná, Prado Velho - Curitiba, PR, CEP: 80215-901, Brasil.

Estudiante de doctorado en Administración de Empresas, Pontifícia Universidade Católica do Paraná, Prado Velho Curitiba, PR, CEP: 80215-901, Brasil.

$\mathrm{PhD}$ candidate in Business Administration, Pontifical

Catholic University of Parana, Prado Velho - Curitiba, PR, CEP: 80215-901, Brazil.

Recebido em junho de 2015 e aceite em julho de 2016. Recibido en junio de 2015 y aceptado en julio de 2016. Received in June 2015 and accepted in July 2016.
Eduardo Damião da Silva

\section{eduardo.damiao@pucpr.br}

Doutorado em Management Sciences, Escuela Superior

de Administración y Dirección de Empresas, ESADE,

Espanha. Professor Titular e Decano, Pontifícia

Universidade Católica do Paraná, Escola de Negócios,

Prado Velho - Curitiba, PR, CEP: 80215-901, Brasil.

Doctorado en Ciencias de la Administración, Escuela Superior de Administración y Dirección de Empresas,

ESADE, España. Profesor y Decano de la Universidad de Paraná, Escuela de Negocios, Prado Velho - Curitiba, Brasil, CEP: 80215-901, Brasil.

$\mathrm{PhD}$ in Management Sciences Program, Escuela Superior de Administración y Dirección de Empresas, ESADE, Spain. Full Professor and Dean, Pontifical Catholic University of Parana, Business School, Prado Velho - Curitiba, PR, CEP: 80215-901, Brazil. 
Quando a relação entre o agente e o principal é conflitante, a consequência é a assimetria de informação, que ocorre quando os agentes estabelecem transações nas quais detêm informações quantitativas ou qualitativas superiores as demais partes envolvidas, trazendo prejuízos, financeiros ou não, para a empresa. Embora o agente deva tomar decisões em favor do principal, muitas vezes ocorrem momentos em que os interesses da empresa divergem dos daquele. $\mathrm{O}$ viés da separação entre o controle e a propriedade surge pela possibilidade de contratação de agentes externos (Jensen e Meckling, 1976).

As informações que a empresa possui são fundamentais para a tomada de decisão: oferecem suporte para realizar atividades essenciais. Assim, é importante que seja considerada com primazia pelos gestores. Situações em que os proprietários se distanciam do controle das empresas, fazem com que estes deixem de suportar todas as informações disponíveis e que o controle seja realizado muitas vezes por pessoas externas, contratadas para este fim específico. Neste sentido, se espera que os indivíduos contratados (agentes) atuem em seus papéis aos quais foram designados e sejam profissionais ao ponto de transferir todas as informações importantes para o proprietário.

A assimetria de informação torna-se melhor no longo prazo, pois as relações entre o principal e o agente tendem a se fortalecer com o tempo, mas no curto prazo será maior, e, assim, se faz necessária a elaboração de contratos baseados em resultados mais atraentes (Eisenhardt, 1989). O conflito de agência surge quando ocorre assimetria de informação e as informações se tornam incompletas quando nem agente nem principal conhecem todas as informações, e, deste modo, são falhas e inconclusas para um ou para outro. Milgron e Roberts (1992) afirmam que a assimetria informacional pode ser considerada como uma situação em que uma das partes, agente ou principal, não detém a informação necessária e relevante para analisar o contrato em que está inserido. Desta forma, podem ocorrer transações vantajosas e desvantajosas, que inviabilizam projetos, ocasionam o direcionamento incorreto dos recursos e não proporcionam o retorno desejado.

Alguns estudos foram realizados, relacionando-se a assimetria de informação com o desempenho financeiro de empresas. Ghani et al. (2015) observaram, em empresas de capital aberto não listadas em bolsa, que quanto mais alta for a assimetria de informação, mais restritas serão as fontes externas de captação de capital e venda de investimentos financeiros, e, consequentemente, seu desempenho financeiro será reduzido. Medeiros (2014) observou acréscimo dos níveis de transparência das empresas em relação a investidores, credores e demais interessados, ocasionando uma maior oferta de créditos financeiros e, complementarmente, tal pode provocar o melhor desempenho financeiro.

Tendo em vista o contexto apresentado, este estudo pretende responder à seguinte pergunta de pesquisa: existe influência da assimetria de informação no desempenho financeiro das empresas de capital aberto? E como objetivo
A relevância deste estudo consiste em incorporar nos estudos sobre assimetria de informações aspectos relacionados a estrutura de governança corporativa, considerando elementos sobre acesso às informações, conteúdo das informações públicas, estrutura do conselho de administração e estrutura de propriedade e controle. 
pretende-se verificar a influência da assimetria de informação no desempenho financeiro das empresas de capital aberto com ações listadas na BM\&FBOVESPA $^{1}$. A relevância deste estudo consiste em incorporar nos estudos sobre assimetria de informações aspectos relacionados a estrutura de governança corporativa, considerando elementos sobre acesso às informações, conteúdo das informações públicas, estrutura do conselho de administração e estrutura de propriedade e controle.

\section{Fundamentos teóricos}

\section{Teoria da agência e conflito de agência}

A teoria da agência tem por finalidade analisar os conflitos que resultam da separação entre a propriedade e o controle de capital, reduzindo os riscos aos investidores e tornando mais simétrica as informações. Assim, possibilita que os acionistas participem de forma mais segura das decisões da empresa. Eisenhardt (1989) questiona o que é teoria de agência. Alguns autores afirmam que a teoria de agência acentua como os mercados de capital podem afetar a firma, enquanto outros não fazem referência aos mercados de capital em absoluto.

A teoria de agência preocupa-se com a resolução de dois problemas que podem ocorrer nas relações de agência. O primeiro é o de agência, que surge quando os desejos de agente e principal entram em conflito, assim torna-se difícil ou caro para o principal verificar o que o agente está realizando de fato. O segundo é o problema do risco, que surge quando o principal e o agente têm atitudes diferentes em direção ao risco (Eisenhardt, 1989), esta questão se refere ao problema de que ambos podem preferir ações diferentes por causa das preferências dos riscos também diferentes.

A relação de agência pode ser entendida como um contrato no qual existe uma relação entre uma pessoa que contrata (principal) e outra que é contratada (agente), para que seja realizado um serviço ou um trabalho em favor do principal (Jensen e Meckling, 1976). Nesta relação, decisões e ações são realizadas visando maximizar o valor da empresa e espera-se que o agente não contrarie os interesses do principal. A relação entre o principal e o agente pode implicar em custos de agência, pois ambos podem ter visões e metas diferentes, e o perfil com relação ao risco a ser assumido também pode divergir.

Jensen e Meckling (1976) exploraram a estrutura de propriedade da corporação, inclusive como a propriedade de capital por gerentes alinha interesses dos gerentes com os dos proprietários. Fama (1980) discutiu o papel de capital eficiente e mercados de trabalho como mecanismos de informação que são usados para controlar o comportamento egoísta de executivos superiores. Por sua vez, Fama e Jensen (1983) descreveram o papel do conselho de diretores como um sistema de informação que os acionistas, dentro de grandes corporações, podem usar para controlar o oportunismo de executivos de topo. 
É, em geral, impossível para o principal ou o agente manter a relação de agência a um custo zero e assegurar que o agente tomará decisões de nível ótimo do ponto de vista do principal. Na maioria das relações de agência, o principal e o agente incorrerão em custos de monitoramento e de concessão de garantias contratuais e, além disso, haverá algum nível de divergência entre as decisões do agente e as decisões que maximizariam o bem-estar do principal (Jensen e Meckling, 1976). Segundo os autores, esses custos de agência podem ser definidos como: i) despesas de monitoramento por parte do principal; ii) despesas com a concessão de garantias contratuais por parte do agente.

A assimetria informacional pode ser considerada como uma situação em que uma das partes, agente ou principal, não detém a informação necessária e relevante para analisar o contrato em que está inserido, desta forma podem ocorrer transações vantajosas e desvantajosas, podendo inviabilizar projetos e ocasionando o direcionamento incorreto dos recursos (Milgron e Roberts, 1992). Para evitar conflitos de agência, Jensen e Mackling (2008) sugerem que sejam considerados: (i) direito de propriedade, que incluiu os comportamentos que deverão ser adotados pelas partes, e que serão definidos previamente nos contratos, os custos e as recompensas que competem a eles e; (ii) custos de agência, que incluem serviços executados pelos agentes em nome do principal, as despesas de monitoramento das atividades dos agentes ao apresentarem conduta oportunista, as despesas com concessão de garantias e o custo residual de acordo com a perda relacionada a conduta divergente do agente.

Os custos de agência são comuns na firma, dependem de regulamentação e das pessoas envolvidas na elaboração dos contratos. Eisenhardt (1989) relaciona a teoria de agência com a teoria dos custos de transação de Williamson, pois ambas compartilham suposições do egoísmo e da racionalidade limitada (Eisenhardt, 1989). Na teoria de agência existem atitudes de riscos do principal e do agente, incerteza de resultado e sistemas de informação. Desta forma, as duas teorias compartilham uma ascendência na economia, mas cada uma tem o seu próprio foco e diversas variáveis independentes únicas.

\section{Assimetria da informação}

As informações que as empresas possuem, seja sobre oportunidades de investimentos, fornecedores ou concorrentes, são fundamentais para a tomada de decisões; assim, a informação necessita ser conduzida com prioridade pela empresa. Situações nas quais os proprietários se distanciam do controle das empresas, fazem com que estes deixem de suportar todas as informações disponíveis, e, nestes casos, o controle é realizado muitas vezes por pessoas externas, contratadas para este fim específico. Assim, espera-se que os indivíduos contratados (agentes) atuem em seus papéis aos quais foram designados e sejam profissionais, ao ponto de transferir todas as informações importantes para o proprietário.
Na teoria de agência existem atitudes de riscos do principal e do agente, incerteza de resultado e sistemas de informação. Desta forma, as duas teorias compartilham uma ascendência na economia, mas cada uma tem o seu próprio foco e diversas variáveis independentes únicas. 
A assimetria pode ocasionar problemas ao mercado de capitais (Healy e Palepu, 1996). Myers e Majluf (1984) afirmam que os preços das ações das empresas podem ser valorizados de forma errônea quando os investidores possuem menos informações sobre o valor da empresa. No mercado de capitais, a assimetria de informação pode ser mensurada de diversas formas, devido ao mercado ser fortemente regulamentado e fiscalizado.

Alguns estudos investigaram a assimetria de informação de diferentes formas. Ghani et al. (2015) evidenciam que a redução da transparência de informações das empresas ocasiona uma maior dificuldade de desempenho, pois elas terão maiores dificuldades de obter crédito financeiro e de negociarem suas ações para atividades e fins inerentes a elas. Assim sendo, quanto mais alta for a assimetria de informação, mais restritas serão as fontes externas de captação de capital e venda de investimentos financeiros (Ghani et al., 2015).

A volatilidade, como medida de assimetria informacional, foi utilizada por Halov e Heider (2005). Os autores argumentaram que, quando as ações flutuam muito antes de sua emissão, podem apresentar custo de seleção adversa da dívida bem maior que as empresas que tiveram ativos estáveis, fazendo com que o investidor externo saiba menos sobre o risco do investimento que irá fazer se a ação que irá adquirir flutuar muito antes de sua emissão.

Medeiros e Quinteiro (2005) identificaram uma relação inversa entre a volatilidade e a divulgação de informações financeiras relevantes entre as empresas. Os autores analisaram uma amostra de 30 empresas brasileiras listadas na BOVESPA, considerando apenas a volatilidade das ações e a transparência das informações destas empresas. Seus achados indicaram que as empresas com maiores níveis de divulgação apresentaram menor volatilidade no retorno de suas ações. Tavares et al. (2014) analisaram o retorno do investimento em ações e a volatilidade das empresas de capital aberto, e seus achados demonstram que pode haver uma relação entre o retorno maior das ações e uma sensibilidade maior de sua volatilidade.

No que tange a liquidez das ações negociadas em bolsa de valores, Agarwal e O'Hara (2007) afirmam que quando a assimetria de informação aumenta, pode ocasionar declínios na liquidez. Uma constatação importante sobre o assunto, apresentada por Amihud e Mendelson (1986), é a necessidade de haver uma relação de forma inversa entre a liquidez e o retorno das ações. Isso se deve ao fato de que as estratégias que os investidores utilizam em seus investimentos e diversificação de suas carteiras de ações não são úteis frente à sua baixa liquidez, e, para contrabalancear isso, o retorno deverá ser maior se a liquidez for menor.

A intensidade do negócio também pode ser considerada uma medida de assimetria de informação, pois quanto maior a quantidade de informações disponibilizadas publicamente pelas empresas, tornando favorável a emissão de ações, menor será a assimetria de informação e maior será a intensidade com que ocorre a negociação dessas ações (Dierkens, 1991). 
As boas práticas de governança corporativa sugerem que as empresas definam os papéis dos órgãos envolvidos na gestão de forma clara. Por meio da estrutura de governança de uma empresa, as informações são evidenciadas em maior quantidade e a qualidade alinha os interesses dos investidores e da administração (Tirole, 2001), e reduz o incentivo da administração para distorcer a divulgação das informações (Leuz et al., 2003).

A disponibilidade de informações é imprescindível para que os recursos sejam alocados de forma eficiente. A ausência de informações confiáveis torna difícil a alocação de recursos financeiros e humanos na empresa. Desta forma, a simetria de informações reduz o risco dos investidores tomarem decisões equivocadas e os auxilia na escolha da alocação de seus recursos frente as diversas opções de investimento que o mercado oferece (Bushman e Smith, 2001).

A assimetria de informação, segundo Akerlof (1970), pode ser considerada como uma falha do mercado, que pode afetar decisões relacionadas com a alocação de recursos. Também, pode ocorrer pela existência de diversos mercados nos quais as informações precisas podem ser difíceis ou caras de se conseguir, relacionadas à qualidade de bens, aos serviços prestados, ou, ainda, aos investimentos a serem feitos. O retorno do investimento em ações pode estar relacionado com essa assimetria de informação, que, por sua vez, pode ser operacionalizada por diversos fatores.

Como uma alternativa para redução da assimetria de informação entre investidores e empresas surge a governança corporativa, a qual intenta para maior transparência de informações internas de estrutura e financeiras, disponíveis aos investidores, potenciais investidores, e parceiros, entre outros. A respeito disso, Almeida et al. (2010) verificaram, no período entre 2003 e 2007, uma melhora na transparência de informações por parte das empresas relativas aos relatórios financeiros; contudo evidenciaram que poucas se destinam a trazer informações a respeito do valor remunerado ao diretor geral e aos membros do conselho.

\section{Procedimentos metodológicos}

A abordagem desta pesquisa é quantitativa, e para tanto foram utilizadas técnicas estatísticas multivariadas, e, quanto ao horizonte temporal, é transversal (cross-section) com dados que descrevem as variáveis em um único ponto de tempo (Hair et al., 2005), compreendendo informações referentes ao ano de 2013. Os dados foram coletados por meio do software Economática e conferidos com os constantes no website da BOVESPA, por setor e por amostragem. Do total das empresas que compõe a população do estudo, foram excluídas as que não haviam publicado suas informações consolidadas no final do ano de 2013 e as que possuíam informações faltantes. A amostra final ficou composta por 158 empresas. As que fazem parte do setor financeiro não foram analisadas em virtude de suas características específicas.
A assimetria de informação, segundo Akerlof, pode ser considerada como uma falha do mercado, que pode afetar decisões relacionadas com a alocação de recursos. Também, pode ocorrer pela existência de diversos mercados nos quais as informações precisas podem ser difíceis ou caras de se conseguir, relacionadas à qualidade de bens, aos serviços prestados, ou, ainda, aos investimentos a serem feitos. 
Para fins do levantamento do desempenho econômico, utilizaram-se os dados das Demonstrações Financeiras Padronizadas: i) Balanço Patrimonial; e ii) Demonstração do Resultado do Exercício no findar do ano de 2013. Foram utilizadas as variáveis Retorno sobre o Ativo (ROA) e Retorno sobre o Patrimônio Líquido (ROE). Para analisar a variável independente assimetria de informação, utilizaram-se variáveis proxies, que se apoiaram na teoria. Estas são especificadas no Quadro 1.

Para a coleta de dados das informações relacionadas ao índice de governança, realizou-se um levantamento das informações de acordo com o estudo de Silveira (2004) e com base em recomendações do código de melhores práticas de governança corporativa do Instituto Brasileiro de Governança Corporativa (IBGC) e da Comissão de Valores Mobiliários (CVM). Para identificar a estrutura da governança corporativa das empresas, foram utilizados 4 grupos de informações, com 21 subgrupos que identificam as informações que as empresas apresentam e que compõem o índice. Os grupos e os subgrupos são apresentados no Quadro 2 (ver p. 32).

As informações referentes ao índice de governança foram criadas por meio de respostas binárias ( 0 e 1 ), sendo 0 para as respostas negativas e 1 para as respostas positivas. Para obter essas informações e identificar a estrutura de governança das empresas, foram analisados os websites das empresas, o Relatório da Administração, o website da BM\&FBOVESPA e suas Demonstrações Financeiras publicadas. Ao final, foi criado um índice que visa representar o número de informações evidenciadas em comparação com o total de questões analisadas.

Quadro 1 Variáveis proxies empregadas com apoio teórico

\begin{tabular}{|c|lc|c|}
\hline Variáveis & \multicolumn{1}{|c|}{ Determinante } & Obra \\
\hline Liquidez e bolsa & $\begin{array}{l}\text { Aumentos na liquidez das ações estão associadas às reduções na } \\
\text { assimetria de informação. Quando uma empresa possui títulos } \\
\text { com liquidez mais alta, o custo de emissão de ações é baixo, } \\
\text { enquanto uma redução em sua liquidez ocasiona custos mais altos. }\end{array}$ & $\begin{array}{c}\text { Agarwal e } \\
\text { O'Hara (2007) }\end{array}$ \\
\hline \multirow{2}{*}{$\begin{array}{c}\text { Intensidade do } \\
\text { negócio }\end{array}$} & $\begin{array}{l}\text { Existe relação inversamente proporcional entre a intensidade e a } \\
\text { assimetria de informação. Quanto maior a intensidade de } \\
\text { negociação de uma empresa menor será a assimetria, pois mais } \\
\text { informações são reveladas. Foram testadas três variáveis: i) o } \\
\text { volume negociado de ações; ii) a negociabilidade ou a quantidade } \\
\text { de negócios e iii) a presença em bolsa, informando o número de } \\
\text { dias que ocorreu pelo menos um negócio com a ação no período } \\
\text { analisado. }\end{array}$ & Dierkens \\
(1991) \\
Volatilidade & $\begin{array}{l}\text { O investidor externo conhece menos informações sobre o risco de } \\
\text { seu investimento se o valor do seu ativo flutuou muito antes de } \\
\text { sua emissão. Desta forma, quanto maior a assimetria, maior a } \\
\text { volatilidade de informações. }\end{array}$ & $\begin{array}{c}\text { Halov e Heider } \\
\text { (2005) }\end{array}$ \\
\hline $\begin{array}{c}\text { Estrutura de } \\
\text { governança }\end{array}$ & $\begin{array}{l}\text { Possuem propriedades que são diferenciadas e que as fazem aptas } \\
\text { para gerir as transações entre os agentes, visando minimizar os } \\
\text { custos de transação objetivando resultados mais eficientes. }\end{array}$ & Fagundes \\
(1997)
\end{tabular}

Fonte: Elaborado pelos autores 
Dada à necessidade de corrigir dados com valores atípicos, foi utilizada a transformação logarítmica (Ln) para a variável média do volume e, desta forma, foram reduzidas algumas assimetrias. Depois foram definidas as variáveis do desempenho econômico, ROE e ROA, e as variáveis proxies que representam a assimetria de informação.

\section{Apresentação e análise dos dados}

$\mathrm{Na}$ estatística descritiva, foram analisados a média das variáveis, o desvio padrão, os valores mínimos e os valores máximos. A Tabela 1 (ver p. 33) apresenta seus resultados para as variáveis do estudo.

A variável ROA apresenta média com valor negativo, relacionado ao fato

Quadro 2 Construção do índice de governança

\begin{tabular}{|c|c|}
\hline GRUPOS & SUBGRUPOS \\
\hline \multirow{7}{*}{$\begin{array}{l}\text { 1. Acesso às } \\
\text { informações }\end{array}$} & 1.1 É possível obter o relatório anual (RA) da empresa por meio da Internet? \\
\hline & 1.2 A empresa possui website? \\
\hline & 1.3 O website dispõe de documentos relativos a governança corporativa? \\
\hline & $\begin{array}{l}\text { 1.4 O website dispõe de apresentações para analistas ou dados que possibilitem } \\
\text { projeções operacionais e financeiras da empresa? }\end{array}$ \\
\hline & $1.5 \mathrm{O}$ website é bilíngue? \\
\hline & $1.6 \mathrm{O}$ website possui uma seção de relações com os investidores? \\
\hline & $\begin{array}{l}\text { 1.7 As informações foram obtidas sem a necessidade de contato direto com a } \\
\text { empresa? }\end{array}$ \\
\hline \multirow{4}{*}{$\begin{array}{l}\text { 2. Conteúdo das } \\
\text { informações } \\
\text { públicas }\end{array}$} & $\begin{array}{l}2.1 \text { O RA inclui uma seção específica dedicada à implementação de princípios de } \\
\text { governança corporativa? }\end{array}$ \\
\hline & 2.2 Os demonstrativos são apresentados em US-GAAP ou IAS-GAP ${ }^{1}$ ? \\
\hline & $\begin{array}{l}2.3 \mathrm{O} \text { RA, website ou algum outro documento corporativo apresenta o valor } \\
\text { adicionado/destruído pelo negócio? }\end{array}$ \\
\hline & $\begin{array}{l}2.4 \text { A empresa produz e publica seus relatórios financeiros legalmente exigidos na } \\
\text { data exigida? }\end{array}$ \\
\hline \multirow{5}{*}{$\begin{array}{l}\text { 3. Estrutura do } \\
\text { conselho de } \\
\text { administração }\end{array}$} & $\begin{array}{l}\text { 3.1 Os cargos de diretor executivo e presidente do conselho de administração são } \\
\text { ocupados por pessoas diferentes? }\end{array}$ \\
\hline & 3.2 A empresa possui um conselho de administração com 5 a 9 membros? \\
\hline & $\begin{array}{l}3.3 \text { Mais que } 80 \% \text { do conselho de administração é composto por conselheiros } \\
\text { externos? }\end{array}$ \\
\hline & $3.4 \mathrm{O}$ conselho de administração possui mandato unificado de um ou dois anos? \\
\hline & 3.5 A empresa possui acordo ou contrato de acionista? \\
\hline \multirow{5}{*}{$\begin{array}{l}\text { 4. Estrutura de } \\
\text { propriedade e } \\
\text { controle }\end{array}$} & 4.1 A empresa emite apenas ações com direito a voto (ON, ações ordinárias)? \\
\hline & $\begin{array}{l}4.2 \text { As ações preferenciais correspondem a menos que } 50 \% \text { do total de ações } \\
\text { ordinárias? }\end{array}$ \\
\hline & $4.3 \mathrm{O}(\mathrm{s})$ controlador(es) possui(em) menos do que $70 \%$ do total de ações ordinárias? \\
\hline & 4.4 A empresa concede tag along aos detentores de ações preferenciais? \\
\hline & $\begin{array}{l}\text { 4.5 A empresa emite ADR (American Depositary Receipts ) e lista suas ações na } \\
\text { Bolsa de Nova Iorque? }\end{array}$ \\
\hline
\end{tabular}

Fonte: Silveira (2004) e com base em recomendações do código de melhores práticas de governança corporativa do IBGC e da CVM 
33| Revista de GESTÃO dos Países de Língua Portuguesa

Tabela 1 Estatística descritiva das empresas

\begin{tabular}{|l|c|c|c|c|}
\hline \multicolumn{1}{|c|}{ Variáveis } & Média & Desvio Padrão & Mínimo & Máximo \\
\hline ROA & $-0,014$ & 0,345 & $-3,234$ & 0,264 \\
\hline ROE & 0,039 & 0,450 & $-2,567$ & 1,781 \\
\hline Liquidez & 0,480 & 0,973 & 0,010 & 8,250 \\
\hline Volatilidade & 45,158 & 43,416 & 15,920 & 460,980 \\
\hline Negociabilidade & 0,484 & 0,893 & 0,010 & 7,520 \\
\hline Presença & 118,928 & 40,177 & 91,532 & 247,177 \\
\hline Media do volume negociado & 9,105 & 1,721 & 4,488 & 13,573 \\
\hline Índice de governança & 0,801 & 0,111 & 0,476 & 0,952 \\
\hline
\end{tabular}

Fonte: Dados da pesquisa, software Stata 11

de haver períodos nos quais as empresas não obtiveram lucro mas prejuízo. Também apresentam patrimônio líquido negativo, deixando a média do indicador de retorno do ativo negativo, mas o ROE positivo. $\mathrm{O}$ índice de governança, que tem variação de 0 a 1 , apresentou valor mínimo de 0,476 e valor máximo de 0,952 . O valor da média dessa variável se apresentou próximo do valor máximo, permitindo inferir que grande parte das empresas está mais próxima do valor máximo e elevando, assim, o valor da média. A variável volatilidade apresenta sua média mais próxima do valor mínimo da mesma variável, permitindo inferir que grande parte das empresas possui sua volatilidade baixa, deixando o valor da média também baixo.

O coeficiente de correlação descreve a relação entre as variáveis (Hair Jr. et al., 2005) que são tidas como correlacionadas quando a mudança em uma delas é associada à mudança em outra. Deste modo, quando uma variável muda, a outra também se altera. Corrar et al. (2007) afirmam que o coeficiente de correlação varia de $-1 \mathrm{a}+1$; onde o sinal indica se a correlação é positiva (quando uma variável cresce, a outra também cresce) ou negativa (quando uma variável cresce, a outra decresce).

Quando há um grau de relação entre as variáveis, quando estão altamente correlacionadas, existe multicolinearidade. Uma colinearidade perfeita existe quando pelo menos um previsor é uma combinação linear perfeita de outros (Field, 2009), quando dois desses previsores estão perfeitamente correlacionados possuem um coeficiente de correlação igual a 1, sendo necessário eliminar uma das variáveis. A Tabela 2 apresenta a correlação entre as variáveis do estudo.

A variável negociabilidade apresentou correlação forte com a variável liquidez. Para confirmar a exclusão de uma dessas variáveis, detectando multicolinearidade, foi utilizada a medida de tolerância (1/VIF), definida como $1-\mathrm{R}^{2}$. Quando seus valores apresentam-se próximos de 0 , indicam que a variável analisada pode ser prevista com alta precisão pelas outras variáveis. $\mathrm{O}$ inverso dessa tolerância é representado pelo variance inflation fator (VIF) (). Este se tiver valores altos apresenta indicativos de multicolinearidade.

Por meio do teste VIF foi confirmada a multicolinearidade entre as 
34 | Revista de GESTÃO dos Países de Língua Portuguesa

Tabela 2 Coeficientes de correlação

\begin{tabular}{|l|c|c|c|c|c|c|}
\hline \multicolumn{1}{|c|}{ Variáveis } & Liquidez & Volatilidade & Negociabilidade & Presenąa & $\begin{array}{c}\text { Média do } \\
\text { volume }\end{array}$ & $\begin{array}{c}\text { Indice de } \\
\text { governança }\end{array}$ \\
\hline Liquidez & 1.000 & & & & & \\
\hline Volatilidade & 0.0935 & 1.000 & & & & \\
\hline Negociabilidade & 0.9965 & 0.1026 & 1.000 & & & \\
\hline Presença & 0.2736 & 0.2232 & 0.2798 & 1.000 & & \\
\hline Media do volume & 0.6033 & -0.1596 & 0.6336 & 0.0857 & 1.000 & \\
\hline Índice de governança & -0.0020 & -0.3626 & 0.0018 & -0.3680 & 0.1882 & 1.000 \\
\hline
\end{tabular}

Fonte: Dados da pesquisa, software Stata 11

variáveis negociabilidade e liquidez, e, desta forma, optou-se pela exclusão da variável negociabilidade, evitando danos para a análise. Após a exclusão desta variável foi realizada a regressão por métodos quadrados ordinários (MQO). Para a análise da heterocedasticidade no modelo de regressão foi utilizado o teste de Breusch-Pagan, e este apresentou um valor $\mathrm{p}$ abaixo de 0,05 , confirmando a existência de heterocedasticidade.

A verificação da autocorrelação também é um importante pressuposto para verificar se os resíduos não estão correlacionados; caso isso se confirme, os parâmetros podem não ter sua eficiência garantida dado o viés nos erros padrões (Drukker, 2003), por mais que sejam corrigidos pelos efeitos da heterocedasticidade. Para a correção simultânea da heterocedasticidade e da autocorrelação foi utilizada a correção de Newey-West (Newey e West, 1987), que se revelou robusta na existência de ambas. E, na sequência, prosseguiu-se com a estimação do modelo de regressão. O primeiro modelo de regressão foi com a utilização da variável dependente ROA.

Pode-se verificar na Tabela 3 que nenhuma das variáveis do modelo mostraram-se significativas, não apresentando influência sobre a variável ROA. O desempenho financeiro, quando medido pelo ROA, não é influenciado pelas variáveis proxies que representam a assimetria de informação. Ferreira (2012) encontrou resultados similares ao não encontrar evidências de que empresas participantes dos níveis de governança são mais eficientes do que as do mercado tradicional.

Estes resultados divergem dos autores Amihud e Mendelson (1989) que

Tabela 3 Resultados da regressão com o ROA

\begin{tabular}{|c|c|c|c|c|c|c|}
\hline ROA & Coeficiente & $\begin{array}{c}\text { Erro } \\
\text { padrão }\end{array}$ & $\mathbf{t}$ & $P>t$ & \multicolumn{2}{|c|}{$\begin{array}{c}\text { Intervalo de confiança } \\
95 \%\end{array}$} \\
\hline Liquidez & $-0,0192$ & 0,0352 & $-0,55$ & 0,586 & $-0,0888$ & 0,0503 \\
\hline Volatilidade & $-0,0032$ & 0,0024 & $-1,35$ & 0,178 & $-0,0079$ & 0,0014 \\
\hline Presença & 0,0005 & 0,0010 & 0,54 & 0,588 & $-0,0014$ & 0,0026 \\
\hline Média do volume & $-0,0045$ & 0,0190 & $-0,24$ & 0,811 & $-0,0421$ & 0,0330 \\
\hline Índice de governança & 0,0086 & 0,1961 & 0,04 & 0,965 & $-0,3787$ & 0,3959 \\
\hline Constante & 0,1083 & 0,2726 & 0,40 & 0,692 & $-0,4302$ & 0,6469 \\
\hline
\end{tabular}

Fonte: Dados da pesquisa, software Stata 11 
analisaram o mercado de ações americano e concluíram que se a liquidez das empresas analisadas aumenta, menor será o spread e maior será o retorno das ações. Os autores justificam esta evidência, por haver um prêmio de liquidez no mercado no período do estudo. Os autores também constataram, em outro estudo, que é necessário haver uma relação inversa entre a liquidez e o retorno das ações, pois as estratégias que os investidores utilizam em seus investimentos e diversificação de suas carteiras de ações não são úteis frente à baixa liquidez das ações, e, para contrabalancear isso, o retorno deverá ser maior se a liquidez for menor (Amihud e Mendelson, 1986).

Outra análise foi realizada, mas desta vez, com a variável dependente ROE, considerando a exclusão da variável negociabilidade. Também foi estimado o teste de Breusch-Pagan, verificando que o modelo apresenta heterocedasticidade, e foi utilizado o método de estimação robusto para correção da heterocedasticidade e autocorrelação. A Tabela 4 apresenta esta regressão.

Das variáveis proxies utilizadas para a assimetria de informação, somente a que representa o índice de governança se revelou significativa, ao nível de $5 \%$ e de forma positiva, indicando que aumentos no índice de governança acarretam em maior desempenho econômico quando representado pelo ROE. Da mesma forma, o efeito contrário também se faz verdadeiro. $\mathrm{O}$ valor obtido do $\mathrm{R}^{2}$ foi de 0,0948 ; apesar de baixo, este considera apenas uma variável proxie.

Os resultados deste estudo corroboram com o de Haniffa e Hudaib (2006) que investigaram a relação entre a estrutura de governança corporativa e o desempenho das empresas listadas na bolsa de valores de Kuala Lumpur. Os seus resultados demonstraram uma relação significativa entre as múltiplas diretorias e o desempenho do mercado. E, com o estudo de Bhagat e Bolton (2008), ao verificarem que, na relação entre governança corporativa e desempenho, os melhores níveis de governança estão positivamente correlacionados com o desempenho. Luo e Yao (2010) identificaram aumentos consideráveis na eficiência bancária, mesmo após um período de crise, e isso ocorreu devido à diversificação da estrutura de propriedade, visando elevar os níveis de governança corporativa e eficiência.

Tabela 4 Resultados da regressão com o ROE

\begin{tabular}{|l|c|c|c|c|c|c|}
\hline \multicolumn{1}{|c|}{ ROE } & Coeficiente & Erro padrão & $\mathbf{t}$ & P>t & \multicolumn{2}{c|}{$\begin{array}{c}\text { Intervalo de confiança } \\
\mathbf{9 5 \%}\end{array}$} \\
\hline Liquidez & 0,0110 & 0,0378 & 0,29 & 0,771 & $-0,0638$ & 0,0859 \\
\hline Volatilidade & $-0,0013$ & 0,0018 & $-0,70$ & 0,486 & $-0,0049$ & 0,0023 \\
\hline Presença & 0,0003 & 0,0012 & 0,27 & 0,788 & $-0,0020$ & 0,0027 \\
\hline Média do volume & 0,0381 & 0,0269 & 1,42 & 0,158 & $-0,0149$ & 0,0913 \\
\hline İ́ndice de governança & 0,6641 & 0,3133 & 2,12 & 0,036 & 0,0450 & 1,2833 \\
\hline Constante & $-0,8254$ & 0,4281 & $-1,93$ & 0,056 & $-1,6710$ & 0,0203 \\
\hline
\end{tabular}

Fonte: Dados da pesquisa, software Stata 11
O desempenho

financeiro, quando medido pelo ROA, não é influenciado pelas variáveis proxies que representam a assimetria de informação.

Ferreira encontrou resultados similares ao não encontrar evidências de que empresas participantes dos níveis de governança são mais eficientes do que as do mercado tradicional. 
No que tange a variável volatilidade, a sua não significância contraria o estudo realizado por Tavares et al. (2014) que analisaram o retorno do investimento em ações e a volatilidade das empresas de capital aberto, e concluíram que podem existir indícios de relação entre o retorno maior das ações e uma sensibilidade maior de sua volatilidade.

\section{Considerações finais}

Este estudo objetivou analisar a influência da assimetria de informação no desempenho financeiro das empresas de capital aberto listadas na BOVESPA. Os resultados obtidos permitem inferir que a assimetria de informação, representada por apenas algumas variáveis proxies, influencia no desempenho das empresas, tanto de forma positiva como negativa.

As empresas não apresentaram influência da assimetria de informação quando analisadas com a variável ROA, permitindo inferir que a assimetria de informação não possui relação com essa variável, e, desse modo, existem outras peculiaridades que afetam o retorno da atividade da empresa. Por sua vez, o desempenho quando representado pelo ROE, mostrou-se influenciado pela assimetria de informação, mas somente pela proxie índice de governança, indicando que se as empresas tornam sua governança corporativa mais transparente o desempenho pelo ROE aumenta.

Ressalta-se que um dos motivos para haver influência do ROE e ausência de influência do ROA na governança corporativa pode ser explicado pela constituição dos indicadores. O ROA representa o retorno da atividade da empresa, podendo ser afetado por fatores relacionados com a operação das empresas. O ROE representa o retorno do investimento dos sócios, podendo ser afetado por fatores relacionados ao patrimônio das empresas, tais como opções por financiamentos, se próprios ou de terceiros, aumento no valor das ações, aumento no valor do patrimônio, entre outros.

Estudos como o de Lima et al., (2015) concluíram que as empresas com níveis mais elevados de governança corporativa possuem um melhor desempenho econômico. Autores como Leuz et al. (2003) e Tirole (2001) ressaltam que empresas com governança corporativa tendem a valorizar sua transparência financeira e operacional, reduzem as assimetrias de informações e, em decorrência disso, alinham os interesses da administração e dos investidores refletindo nos resultados da empresa.

Este estudo contribui ao analisar a assimetria de informação constituída por diversas proxies e ao aliar a governança corporativa em sua composição, propondo uma nova abordagem de assimetria de informação. Macedo e Corrar (2012) evidenciaram em 2005 um desempenho superior nas empresas do setor de distribuição de energia elétrica no Brasil, mas não evidenciaram um desempenho superior nas empresas com maiores níveis de governança corporativa em anos subsequentes. Outra contribuição consiste em oferecer informações aos gestores de empresas de capital aberto
Um dos motivos para haver influência do ROE e ausência de influência do ROA na governança corporativa pode ser explicado pela constituição dos indicadores. 
dado que o desempenho financeiro é influenciado pela assimetria de informação quando se refere ao índice de governança. Assim, a realização de ações para melhoria da governança corporativa, para torná-la mais transparente, conduz a um maior desempenho financeiro, contribuindo para alcançar melhores resultados.

Mas não apenas a assimetria de informação e suas proxies, como as utilizadas neste estudo, influenciam no desempenho das empresas. São necessários estudos sobre não somente fatores financeiros, como custo de capital ou estrutura da dívida, mas também fatores sociais e comportamentais, e é neste caminho que este estudo propõe novas investigações. A limitação do estudo está no fato deste ter sido realizado em um corte transversal, não sendo possível analisar o comportamento das variáveis ao longo do tempo. Sugere-se aprofundá-lo com dados que se refiram a mais de um ano, analisando as variáveis em forma de painel e seu comportamento em um período mais longo do tempo, bem como a análise de variáveis e/ou fatores financeiros e não financeiros que possam influenciar no desempenho da atividade e do investimento das empresas.

\section{Notas}

1. A BM\&FBOVESPA resulta da fusão entre a Bolsa de Mercadorias e Futuros (BM\&F), uma bolsa de comércio brasileira, com a Bolsa de Valores de São Paulo. (N.E.)

2. Normas contábeis internacionais. Generally Accepted Accounting Principles dos Estados Unidos e da IAS (International Accounting Standards). (N.E.)

\section{Referências bibliográficas}

AGARWAL, P. e O’HARA, M. (2007), «Information Risk and Capital Structure». SSRN. Working Paper, http://papers.ssrn.com/sol3/papers.cfm?abstract_id=939663, acedido em 24/09/2014.

AKERLOF, G. (1970), "The market for "lemons": quality uncertainty and the market mechanism». The Quarterly Journal of Economics, 84(3), ago, pp. 488-500.

ALMEIDA, M.A.; SANTOS, J.F.; FERREIRA, L.F.V.M. e TORRES, F.J.V. (2010), «Evolução da qualidade das práticas de governança corporativa: um estudo das empresas brasileiras de capital aberto não listadas na bolsa». Revista de Administração Contemporânea, 14(5), set./out., pp. 907-924.

AMIHUD, Y. e MENDELSON, H. (1986), «Liquidity and stock returns». Financial Analysts Journal, 42(3), pp. 43-48.

AMIHUD, Y. e MENDELSON. H. (1989), «The effects of beta, bid-ask spread, residual risk, and size on stock returns». Journal of Finance, 44(2), jun., pp. 479-486.

BHAGAT, S. e BOLTON B. (2008), «Corporate governance and firm performance». Journal of Corporate Finance, 14(3), pp. 257-273.

BUSHMAN, R. e SMITH, A. (2001), «Financial accounting information and corporate governance». Journal of Accounting and Economics, 32, pp. 237-333.

CORRAR, L.J.; PAULO, E. e DIAS FILHO, J.M. (2007), Análise Multivariada. Atlas, São Paulo.

DIERKENS, N. (1991), «Information asymmetry and equity issues». Journal of Financial and Quantitative Analysis, 26(2), jun., pp. 181-199.

DRUKKER, D. M. (2003), «Testing for serial correlation in linear panel data». The STATA Journal, 3(2), pp. 168-177. 
EISENHARDT, K. (1989), «Agency theory: an assessment and review». Academy of Management Review, 14(1), pp. 57-74.

FAGUNDES, J. (1997), "Custos de transação e impactos sobre política de defesa da concorrência». Revista de Economia Contemporânea, 2, jul./dez., pp. 115-135.

FAMA, E.F. (1980), «Agency problems and the theory of the firm». The Journal of Political Economy, 88(2), pp. 288-307.

FAMA, E.F. e JENSEN, M.C. (1983), «Separation of ownership and control». Journal of Law and Economics, 26(2), pp. 301-325.

FERREIRA, R.N. (2012), «Governança Corporativa e Desempenho: Uma Análise em Empresas Brasileiras de Capital Aberto». Tese de doutorado, Universidade Federal de Lavras, Minas Gerais, Brasil.

FIELD, A. (2009), Descobrindo a Estatística Usando o SPSS. Artmed, Porto Alegre.

GHANI, A.N.A.; MARTELANC, R. e KAYO, E.K. (2015), «Há diferença de restrição de crédito para empresas de capital aberto e fechado no Brasil? Evidência empírica pela abordagem de Cash Flow Sensitivity». Revista de Contabilidade e Finanças, 26(67), pp. 85-92.

HAIR JR., J.F.; ANDERSON, R.E.; TATHAN, R.L. e BLACK, W.C. (2005), Análise Multivariada de Dados. 5. a ed., Bookman, Porto Alegre.

HALOV, N. e HEIDER, F. (2005), «Capital Structure, Risk and Asymmetric Information». SSRN, Working Paper, dec.

HANIFFA, R. e HUDAIB, M. (2006), «Corporate governance structure and performance of Malaysian listed companies». Journal of Business Finance \& Accounting, 33(7-8), pp. 1034-1062.

HEALY, P.M. e PALEPU, K.G. (1996), «Information asymmetry, corporate disclosure, and the capital markers: A review of the empirical disclosure literature». Journal of Accounting and Economics, 31(3), pp. 429-458.

JENSEN, M.C. e MECKLING, W.H. (1976), «Theory of the firm: managerial behavior, agency costs and ownership structure». Journal of Financial Economics, 3(4), pp. 305-360.

JENSEN, M.C. e MECKLING, W.H. (2008), «Teoria da firma: comportamento dos administradores, custos de agência e estrutura de propriedade». Revista de Administração de Empresas, 48(2).

LEUZ, C.; NANDA, D.E. e WYSOCKI, P.D. (2003), «Earnings management and investor protection: an international comparison». Journal of Financial Economics, 69, pp. 505-527.

LIMA, S.H.O.; OLIVEIRA, F.D.; CABRAL, A.C.A.; SANTOS, S.M. e PESSOA, M.N.M. (2015), «Governança corporativa e desempenho econômico: uma análise dos indicadores de desempenho entre os três níveis do mercado diferenciado da BM\&FBOVESPA». REGE Revista de Gestão, 22(2), pp. 187-204.

LUO, D. e YAO, S. (2010), «World financial crisis and the rise of Chinese commercial banks: an efficiency analysis using DEA». Applied Financial Economics, 20(19), pp. 1515-1530.

MACEDO, M.A.D.S. e CORRAR, L.J. (2012), "Análise comparativa do desempenho contábil-financeiro de empresas com boas práticas de governança corporativa no Brasil». Revista Contabilidade e Controladoria, 4(1), pp. 42-61.

MEDEIROS, N.C.D. (2014), «Estrutura de Capital e Assimetria de Informação: Um Estudo em Empresas Brasileiras de Capital Aberto dos Setores Têxtil e de Energia Elétrica». Dissertação de Mestrado, Universidade Federal de Lavras, Minas Gerais, Brasil.

MEDEIROS, O. e QUINTEIRO, L. (2005), «Disclosure of Accounting Information and Stock Return Volatility in Brazil». Social Science Research Network. http://papers.ssrn.com/sol3/papers.cfm?abstract_id=835726, acedido em 29/10/2014.

MILGRON, P. e ROBERTS. J. (1992), Economics, Organizational \& Management. Prentice-Hall, New Jersey.

MYERS, S.C. e MAJLUF, N.S. (1984), «Corporate financing and investment decisions when firms have information that investors do not have». Journal of Financial Economics, 13(2), pp. 187-221. 
$39 \mid$ Revista de GESTÃO dos Países de Língua Portuguesa

NEWEY, W.K. e WEST, K.D. (1987), «A simple, positive semi-definite, heteroskedasticity and autocorrelation consistent covariance matrix». Econometrica, 55(3), pp. 703-708.

SILVEIRA, A.D.M. (2004), «Governança Corporativa e Estrutura de Propriedade: Determinantes e Relação como Desempenho das Empresas no Brasil». Tese de Doutorado, Universidade de São Paulo, Brasil.

TAVARES, M.L.F.; BARBEDO, C.H.S. e ARAÚJO, G.S. (2014), "A influência da assimetria de informação no retorno e na volatilidade das carteiras de ações de valor e de crescimento». Brazilian Business Review, 11(1), pp. 118-136.

TIROLE, J. (2001), «Corporate Governance». Econometrica, 69(1), pp. 1-35.

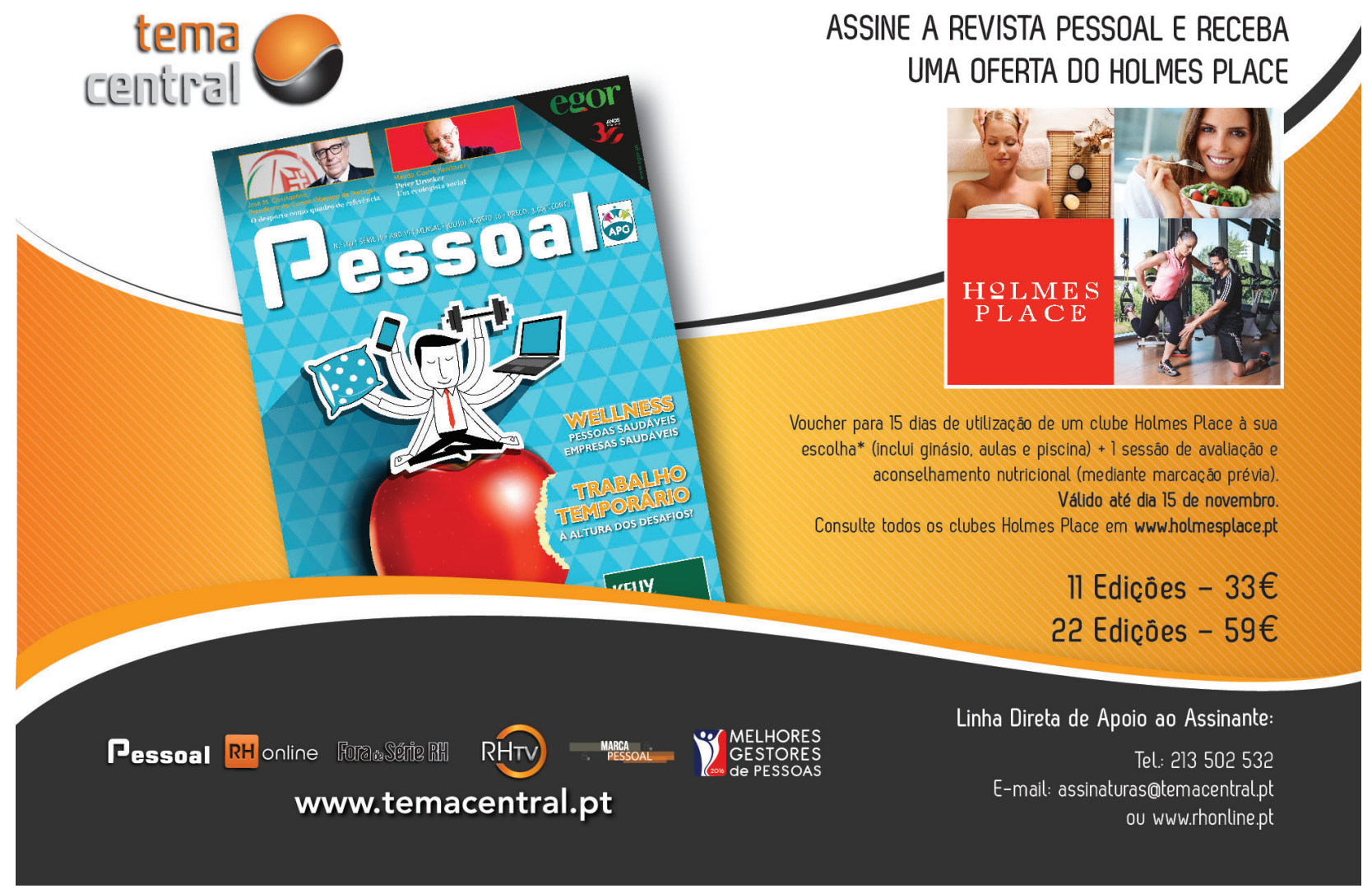

